\title{
MMP-3 polymorphism: Genetic marker in pathological processes (Review)
}

\author{
F.B.A. MUNHOZ ${ }^{1}$, A.L. GODOY-SANTOS ${ }^{2}$ and M.C.L.G. SANTOS ${ }^{1}$ \\ ${ }^{1}$ Department of Cell Biology, University Federal of Paraná, Curitiba PR; \\ ${ }^{2}$ Institute of Orthopedics and Traumatology, University of São Paulo Medical School, São Paulo, Brazil
}

Received March 9, 2010; Accepted July 20, 2010

DOI: $10.3892 / \mathrm{mmr} .2010 .340$

\begin{abstract}
Matrix metalloproteinases (MMPs) are a family of zinc-dependent endopeptidases that are collectively capable of cleaving virtually all extracellular matrix (ECM) substrates and play an important role in diverse physiological and pathological processes. The activity of MMPs is controlled at multiple levels, and the transcriptional regulation of MMPs appears to represent a necessary step in its regulation. MMP-3 is a key member of the MMP family with broad substrate specificity, and is crucial to the connective tissue remodeling process. It is also involved in the turnover of the numerous ECM components. A common functional promoter polymorphism of MMP-3, 5A/6A, affects its activity and has been associated with various diseases. This polymorphism may be used as a genetic marker for certain pathologies to identify individual susceptibility. This review discusses various topics related to MMP-3 in pathological processes, with a focus on the $5 \mathrm{~A} / 6 \mathrm{~A}$ polymorphism.
\end{abstract}

\section{Contents}

1. Introduction

2. Matrix metalloproteinase-3

3. 5A/6A polymorphism of MMP-3

4. Pathological processes and the MMP-3 5A/6A polymorphism

5. Haplotype influence

Correspondence to: Professor Maria C.L.G. Santos, Department of Cell Biology, University Federal of Paraná, Centro Politécnico, Rua Francisco H. dos Santos, Jd. das Américas, 81531-990 Curitiba PR, Brazil

E-mail: mariacristina@ufpr.br

Abbreviations: ECM, extracellular matrix; MMP, matrix metalloproteinase; TIMP, tissue inhibitors of MMP: 5A, 5 consecutive adenines; 6A, 6 consecutive adenines

Key words: metalloproteinases, polymorphism, pathological process, individual susceptibility

\section{Introduction}

The evidence that individual characteristics play an important role in physiological and pathological processes has resulted in the targeted study of genetic polymorphisms in the clinical setting. In this context, mediators that degrade the extracellular matrix (ECM), such as matrix metalloproteinases (MMPs), are highlighted in studies involving inflammatory and degenerative diseases, and principally the prognosis and metastasis of cancer.

Degradation of the ECM is essential in many physiological processes, such as during development, growth and repair of tissue, and the microenvironment plays a central role in controlling both normal and transformed cell functions, as well as normal tissue integrity (1).

MMPs are a pivotal family of zinc enzymes responsible for the degradation of ECM components, including basement membrane collagen, interstitial collagen, fibronectin and various proteoglycans, during normal remodeling and repair processes in development and inflammation. MMPs are also peptidase enzymes responsible for clotting factors, lipoproteins, latent growth factors and chemotactic and cell adhesion molecules $(2,3)$. In this way, MMPs play a key role in the physiologic remodeling of tissues, including embryogenesis and tissue morphogenesis, angiogenesis, cell migration, proliferation, apoptosis, alteration of cell motility, effects on the immune system, wound repair and the inflammatory response (4).

MMPs are a family of more than 25 enzymes. The expression of most MMPs is normally low in tissues and is induced when remodeling of the ECM is required. MMP gene expression is regulated primarily at the transcriptional level, but there is also evidence of the modulation of mRNA stability in response to growth factors and cytokines (5). The promoter region of inducible MMP genes (i.e., MMP-3) shows remarkable conservation of regulatory elements, and their expression is induced by growth factors, cytokines and other environmental factors, such as contact with the ECM (6). The potent proteolytic activities of MMPs are also regulated by conversion of the pro-enzyme to the activated form and the balance with specific tissue inhibitors of metalloproteinases (TIMPs) (7).

MMPs may alter the cell cycle checkpoint controls, promote genomic instability conceivably by affecting cell adhesion, and contribute to tumor initiation and development 
by altering the cellular microenvironment that facilitates tumor formation (8). In fact, excessive or inappropriate expression of MMPs may contribute to the pathogenesis of tissue destructive processes in a wide variety of diseases, including various types of cancer, invasion and metastasis of tumor cells, inflammation and degenerative diseases (9-14).

Many studies have investigated the association between polymorphic variants in MMP candidate genes and several diseases. The aim of our review is to discuss various topics related to MMP-3 in pathological processes, with a focus on the $5 \mathrm{~A} / 6 \mathrm{~A}$ polymorphism.

\section{Matrix metalloproteinase-3}

Matrix metalloproteinase-3 (also called stromelysin-1, STR1 and STMY1) is an important member of the MMP family and degrades collagen types II, IV, V, IX, X and XI, proteoglycans, laminin, fibronectin, gelatins and elastin and other ECM proteins. It also activates other metalloproteinases, such as MMP-1, -2 and -9 (15,16), as well as its own pro-enzyme, pro-MMP-3 (17).

MMP-3 is a key member of the MMP family, with broad substrate specificity. In this way, MMP-3 is crucial to the connective tissue remodeling process; it is involved in the turnover of numerous ECM components (18).

Stromelysin-1 is produced by various types of cells, such as fibroblasts, smooth muscle cells, macrophages, synovial cells and chondrocytes (19). The expression of MMP-3 is primarily regulated at the level of transcription, where the promoter of the gene responds to various stimuli, including growth factors, cytokines, tumor promoters and oncogene products (20). MMP-3 expression is also induced in response to local conditions, such as mechanical loading (21) and inflammation (22).

MMP-3 may be particularly significant to arterial wall remodeling, as it potentially contributes to the development of structural alterations in the vessel wall by degradation of ECM proteins (23).

MMP-3 is known to lyse basal membrane collagen, and may play a role in both local invasiveness and metastatic spread, the latter of which involves the ability of neoplastic cells to cross the basal membrane of both the epithelium and the vascular endothelium. MMP-3 overexpression by some tumor types is implicated in tumor angiogenesis, invasion and metastasis (16).

\subsection{A/6A polymorphism of MMP-3}

Polymorphisms represent natural sequence variants (alleles). They may occur in more than one form that is present in at least $1 \%$ of a population and is considered biologically normal (24). A polymorphism exerts allele-specific effects on the regulation of gene expression or function of the coded protein, thus underlying individual differences in various biological traits and in susceptibility to disease (23).

A common functional promoter polymorphism of MMP-3 has been associated with various diseases. The MMP-3 gene is located adjacent to the telomere side of the MMP-1 gene on 11q22 (23). A naturally occurring and common polymorphism (rs3025058) affects the MMP-3 promoter at a position -1171 , where either 5 or 6 consecutive adenines (5A/6A) alter transcription factor binding and affect MMP-3 promoter activity (23).

The 5A allele was found to have greater promoter activity in various experiments with cell cultures, such as fibroblasts and vascular smooth muscle cells (23); however, this has not yet been confirmed in human tissue.

In vitro data suggest that the $5 \mathrm{~A} / 6 \mathrm{~A}$ polymorphism in the MMP-3 gene promoter is potentially functionally relevant, where the $5 \mathrm{~A}$ allele is associated with higher and the $6 \mathrm{~A}$ allele with lower transcriptional activity $(25,26)$. DNA-protein interaction assays showed that nuclear protein binds more strongly to the $6 \mathrm{~A}$ sequence than to the $5 \mathrm{~A}$ sequence, suggesting that it may be a transcriptional repressor (23).

The control of MMP-3 expression in vivo is complex and not well understood, and could be subject to modulation by other transcription or post-transcription factors, such as cytokines $(27,28)$; one of its polymorphisms is located within the interleukin-1 responsive element for several transcriptional regulators (29).

\section{Pathological processes and the MMP-3 5A/6A polymorphism}

MMP-3 plays an important role in connective tissue remodeling during tissue repair, cell migration, angiogenesis, tissue morphogenesis and growth. These physiological processes require accurate control; however, the disruption of this balance may lead to several pathological states.

The inflammatory and degenerative reaction is orchestrated by several molecules belonging to different families of inflammatory mediators, such as cytokines, chemokines, adhesion molecules and proteolytic enzymes $(30,31)$. Importantly, plasma levels and/or functional activity of these inflammation determinants may be strongly influenced by functional single nucleotide polymorphisms of the corresponding genes, with important clinical implications. This is the case of the polymorphism of MMP-3, which has important roles at different stages in inflammatory and degenerative processes.

The 5A/6A polymorphism in the MMP-3 gene promoter was previously investigated in patients with cardiovascular disease, suggesting an association with more severe coronary atherosclerosis $(23,32,33)$. The $5 \mathrm{~A}$ allele has been associated with acute coronary events $(34,35)$, abdominal aortic and intracranial aneurysms (36) and peripheral arterial occlusive disease (37), all of which may reflect increased matrix degradation. By contrast, the 6A allele has been associated with carotid intima-media thickening (38) and the progression of coronary artery disease (32), restenosis after balloon angioplasty (39), angiographic coronary atherosclerotic lesion growth $(32,40)$ and stenosis $(41,42)$, suggesting that a lower expression may result in matrix accumulation, faster arterial wall thickening and plaque progression (43).

Atherosclerosis is characterized by a complex multi-factorial pathophysiology, and extensive expression of the MMP-3 gene was found to be particularly localized in plaque regions prone to rupture, such as the fibrous cap and its adjacent tissues (44). Other MMPs also influence arterial wall pathologies, but while some studies have identified local expression of MMP-3 in coronary plaque (45), other MMPs, such as MMP-1 and -9, were found mainly in carotid plaque (46). 
Table I. Association of the 5A/6A polymorphism in the MMP-3 gene with various diseases.

\begin{tabular}{|c|c|c|}
\hline & Disease & Reference \\
\hline \multicolumn{3}{|l|}{ Allele } \\
\hline $5 \mathrm{~A}$ & Rheumatoid arthritis & Scherer et al, 2010 (75) \\
\hline $5 \mathrm{~A}$ & Lumbar disc degeneration & Yuan et al, 2010 (10) \\
\hline $5 \mathrm{~A}$ & Myopia & Hall et al, 2009 (76) \\
\hline $6 \mathrm{~A}$ & Ankylosing spondylitis & Wei et al, 2009 (77) \\
\hline $6 \mathrm{~A}$ & Angiographic coronary plaque & Chen et al, 2009 (52) \\
\hline $5 \mathrm{~A}$ & Coronary artery disease & Ozkök et al, 2008 (78) \\
\hline $6 \mathrm{~A}$ & Susceptibility to carotid atherosclerosis & Djurić et al, 2008 (79) \\
\hline $5 \mathrm{~A}$ & Peripheral arterial occlusive disease & Flex et al, 2007 (37) \\
\hline $5 \mathrm{~A}$ & Migraine & Kara et al, 2007 (80) \\
\hline $5 \mathrm{~A}$ & Oral cancer & Vairaktaris et al, 2007 (60) \\
\hline $5 \mathrm{~A}$ & Breast cancer progression & Holliday et al, 2007 (59) \\
\hline $5 \mathrm{~A}$ & Vascular dementia & Flex et al, 2006 (85) \\
\hline $5 \mathrm{~A}$ & Acute coronary syndrome & Liu et al, 2006 (81) \\
\hline $5 \mathrm{~A}$ & Hepatocellular carcinoma & Okamoto et al, 2005 (61) \\
\hline $5 \mathrm{~A}$ & Acute myocardial infarction & Liu et al, 2003 (82) \\
\hline $6 \mathrm{~A}$ & Severity of rheumatoid arthritis & Constantin et al, 2002 (19) \\
\hline $5 \mathrm{~A}$ & Breast cancer & Ghilardi et al, 2002 (83) \\
\hline $6 \mathrm{~A}$ & Carotid stenosis & Ghiraldi et al, 2002 (38) \\
\hline \multicolumn{3}{|l|}{ Haplotype } \\
\hline 2G/1G - 6A/5A (MMP-1 - MMP-3) & Coronary artery disease & Horne et al, 2008 (12) \\
\hline 2G/2G - 6A/6A (MMP-1 - MMP-3) & Colorectal cancer & Lièvre et al, 2006 (13) \\
\hline 1G-6A-82A-1082G (MMP-1 - MMP-3 - MMP-12) & Lung cancer & Su et al, 2006 (14) \\
\hline 2G-6A (MMP-1 - MMP-3) & Colorectal cancer susceptibility & Hinoda et al, 2002 (84) \\
\hline
\end{tabular}

Although these studies suggest a profound influence of the MMP-3 genotype on matrix composition, the potential influence of this polymorphism on the elastic properties of the large arteries has not been clarified (47). Given the known associations between large artery stiffness and cardiovascular risk (48), particularly myocardial ischemic risk (49), it would be useful from a risk stratification perspective to understand how the MMP-3 genotype affects large artery stiffness.

In Kawasaki disease, a multi-systemic type of vasculitis including coronary involvement, the MMP-3 6A/6A genotype may be an independent risk factor for coronary artery lesions (50).

In diabetes patients, the MMP-TIMP system in vessel walls is substantially dysregulated (51), demonstrating that polymorphisms of MMP-3 affect angiographic coronary plaque progression in non-diabetic and type 2 diabetic patients (52).

A previous study found that the MMP-3 promoter genotype was associated with intervertebral disc degeneration in an elderly group ( $>64$ years of age), but not in subjects less than 28 years of age. In fact, the accumulative effects resulting from differences in MMP-3 expression when the genotypes are compared may be significant in ageing (53). Kauppila (54) suggested that intervertebral disc degeneration may be due to disease of the lumbar artery. This indicates that the association of the MMP-3 promoter polymorphism and intervertebral disc degeneration may be related to arterial disease (53).
As summarized in Table I, this polymorphism has been associated with susceptibility to a variety of diseases, including cancer. Tumor invasion, metastasis and angiogenesis require controlled degradation of the ECM; therefore, it is clear that the expression of MMPs is associated with the invasion and metastasis of various malignancies.

The relationship between the MMP-3 5A/6A polymorphism and susceptibility to cancer remains ambiguous (55). For example, its association with breast cancer is controversial. While certain studies $(38,56)$ have correlated the $5 \mathrm{~A}$ allele with breast cancer susceptibility and have demonstrated that $5 \mathrm{~A}$ homozygosity confers a worse prognostic, this has not been confirmed in other studies $(57,58)$.

Holliday et al (59) suggested that, in women with breast cancer, a highly expressed MMP-3 genotype may promote tumor progression to a greater extent. Vairaktaris et al (60) demonstrated the association between the MMP-3 5A/6A polymorphism and oral cancer. This polymorphism was also found to influence hepatocellular carcinoma (61), while negative findings have been reported for endometrial cancer (62), brain astrocytoma (63), colorectal cancer (64), renal cell carcinoma (55) and ovarian cancer (65).

Although this polymorphism alone does not influence certain diseases, it has been demonstrated that the MMP haplotype, including the $5 \mathrm{~A} / 6 \mathrm{~A}$ polymorphism in MMP-3, is strongly associated with several pathological processes, including cancer. These findings may explain why the asso- 
ciation of MMP-3 5A/6A with cancer was less unambiguous in previous case-control studies. In fact, carcinogenesis, like most diseases, is a multicellular and multistage process, and different genes that metabolize various types of proteins may be involved in its stages.

\section{Haplotype influence}

Haplotypes are a combination of alleles at multiple loci that are transmitted together on the same chromosome. Haplotype effects may provide more complete and reliable information than single polymorphism analysis, which may contribute only partially to the MMP pathway.

A previous study suggested that genetic variations in the MMP family, including MMP-1, $-3,-8,-12$ and -9 , are associated with bladder cancer risk. Heavy carcinogen exposure may overwhelm some of the genetic effects of MMP polymorphisms. This confirms the importance of favoring a multigenic pathway-based approach to risk assessment (66).

It appears that there are at least two explanations for why a phenotype is associated with a haplotype, but not with the individual polymorphisms that make up the haplotype. First, a functional effect on gene expression is dependent on the interaction between two or more polymorphisms (67); second, haplotypes generally have a higher probability than individual polymorphisms of showing useful linkage disequilibrium with an unknown causal variant (68). However, for a complete explanation, analysis characterizing the nuclear proteins involved and their interactions is required.

In fact, the MMP-3 5A/6A polymorphism is in linkage disequilibrium with the MMP-1 $1 \mathrm{G} / 2 \mathrm{G}$ polymorphism (63). Fang et al (69) showed that the 1G/6A haplotype may play a protective role in the development of adult astrocytoma, whereas the MMP-3 5A/6A polymorphism is not necessarily an independent factor influencing susceptibility to astrocytoma in individuals from northern China.

The MMP 2G/6A haplotype was associated with lower risk of lymphatic metastasis of lung cancer when compared to the $1 \mathrm{G} / 5 \mathrm{~A}$ haplotype in a Chinese population (69). However, in a US population, another haplotype $(1 \mathrm{G} / 6 \mathrm{~A} / 82 \mathrm{~A} / 1082 \mathrm{G})$, including MMP-1 (1G/2G), MMP-3 (5A/6A) and MMP-12 $(-82 \mathrm{AG}, 1082 \mathrm{~A} / \mathrm{G})$, showed an association with a higher risk of lung cancer among never smokers (14). These conflicting results are explained by ethnic variations in the polymorphisms.

In fact, the association between different diseases and the frequencies of diverse polymorphisms has been shown to vary with race/ethnicity $(70,71)$. In the $5 \mathrm{~A} / 6 \mathrm{~A}$ polymorphism in MMP-3, a high frequency of the 6A allele is found in approximately $50 \%$ of Caucasian populations (40). This allelic frequency is in agreement with that reported in Australian (47), British (72) and Swedish (73) populations. However, Lanfear et al (74) showed that the 6A allele is more common in African American than in European American subjects, suggesting a potential genetic contribution to the observed racial differences in genotype distribution. A differential impact of this polymorphism, if present, could suggest either that they are in linkage with a causative variant or that their influence requires other genetic modifiers that may differ between races.
Environmental influences, such as diet and smoking (39), appear to have an important interaction with the MMP-3 genotype, and may be particularly important in explaining ethnic differences in the relationship between the MMP-3 genotype and coronary artery disease (40).

Therefore, in order to clarify the contribution of genetic polymorphisms to the development and progression of disease, it is important to analyze such genotype distributions and allele frequencies between diverse races. This may help confirm the positive correlation reported in different populations.

The 5A/6A polymorphism in MMP-3 may contribute to the pathogenesis of tissue destructive processes in a wide variety of diseases. However, analysis is required to determine whether its effect is buffered or intensified in a haplotype with other MMP polymorphisms, which participle in a complex network of interactions in such diseases in a particular manner in each ethnic population. Thus, the discovery of genetic markers related to pathologies becomes clinically invaluable for identifying susceptible individuals. Further study of polymorphisms in the MMP-3 gene will provide additional insight into the biology of diverse diseases, and will aid in a better understanding of the molecular influence of polymorphisms.

\section{References}

1. Howlett AR and Bissell MJ: The influence of tissue microenvironment (stroma and extracellular matrix) on the development and function of mammary epithelium. Epithelial Cell Biol 2: 79-89, 1993.

2. Sternlicht MD and Werb Z: How matrix metalloproteinases regulate cell behavior. Annu Rev Cell Dev Biol 17: 463-516, 2001.

3. Nagase H and Woessner JF Jr: Matrix metalloproteinases. J Biol Chem 274: 21491-21494, 1999.

4. Cauwe B, van den Steen PE and Opdenakker G: The biochemical, biological, and pathological kaleidoscope of cell surface substrates processed by matrix metalloproteinases. Crit Rev Biochem Mol Biol 42: 1113-1185, 2007.

5. Johnsen M, Lund LR, Romer J, Almholt K and Danø K: Cancer invasion and tissue remodeling: common themes in proteolytic matrix degradation. Curr Opin Cell Biol 10: 667-671, 1998.

6. Shapiro SD: Matrix metalloproteinase degradation of extracellular matrix: biological consequences. Curr Opin Cell Biol 10: 602-608, 1998.

7. Chakraborti S, Mandal M, Das S, Mandal A and Chakraborti T: Regulation of matrix metalloproteinases: an overview. Mol Cell Biochem 253: 269-285, 2003.

8. Zhu Y, Spitz MR, Lei L, Mills GB and Wu X: A single nucleotide polymorphism in the matrix metalloproteinase-1 promoter enhances lung cancer susceptibility. Cancer Res 61: 7825-7829, 2001.

9. Yi YC, Chou PT, Chen LY, Kuo WH, Shih-Chu Ho E, Han CP and Yang SF: Matrix metalloproteinase-7 (MMP-7) polymorphism is a risk factor for endometrial cancer susceptibility. Clin Chem Lab Med 48: 337-344, 2010.

10. Yuan HY, Tang Y, Liang YX, Lei L, Xiao GB, Wang S and Xia ZL: Matrix metalloproteinase-3 and vitamin D receptor genetic polymorphisms, and their interactions with occupational exposure in lumbar disc degeneration. J Occup Health 52: 23-30, 2010.

11. Erbek SS, Yurtcu E, Erbek S and Sahin FI: Matrix metalloproteinase-9 promoter gene polymorphism $(-1562 \mathrm{C}>\mathrm{T})$ in nasal polyposis. Am J Rhinol Allergy 23: 568-570, 2009.

12. Horne BD, May HT, Anderson JL, et al: Usefulness of routine periodic fasting to lower risk of coronary artery disease in patients undergoing coronary angiography. Am J Cardiol 102: 814-819, 2008.

13. Lièvre A, Milet J, Carayol J, et al: Genetic polymorphisms of MMP1, MMP3 and MMP7 gene promoter and risk of colorectal adenoma. BMC Cancer 6: 270, 2006. 
14. Su L, Zhou W, Asomaning K, et al: Genotypes and haplotypes of matrix metalloproteinase 1,3 and 12 genes and the risk of lung cancer. Carcinogenesis 27: 1024-1029, 2006.

15. Nagase $\mathrm{H}$ and Okada Y: Proteinases and matrix degradation In: Textbook of Rheumatology. Kelley W (ed). WB Saunders, Philadelphia, pp323-341, 1997.

16. Johansson N, Ahonen M and Kahari VM: Matrix metalloproteinases in tumor invasion. Cell Mol Life Sci 57: 5-15, 2000.

17. Woessner J: Matrix metalloproteinases and their inhibitors in connective tissue remodeling. FASEB J 5: 2145-2154, 1991

18. Lesauskaite V, Sinkūnaite G, Benetis R, et al: Matrix metalloproteinase-3 gene polymorphism and dilatative pathology of ascending thoracic aorta. Medicina 44: 386-391, 2008.

19. Constantin A, Lauwers-Cancès V, Navaux F, et al: Stromelysin 1 (matrix metalloproteinase 3) and HLA-DRB1 gene polymorphisms - association with severity and progression of rheumatoid arthritis in a prospective study. Arthritis Rheum 46: 1754-1762, 2002.

20. Buttice G, Quinones S and Kurkinen M: The AP-1 site is required for basal expression but is not necessary for TPA-response of human stromelysin gene. Nucleic Acids Res 19: 3723-3731, 1991.

21. Leong DJ, Gu XI, Li Y, et al: Matrix metalloproteinase-3 in articular cartilage is upregulated by joint immobilization and suppressed by passive joint motion. Matrix Biol: Feb. 12, 2010 (E-pub ahead of print).

22. Ito A, Mukaiyama A, Itoh Y, et al: Degradation of interleukin 1beta by matrix metalloproteinases. J Biol Chem 271: 14657-14660, 1996.

23. Ye S, Eriksson P, Hamsten A, Kurkinen M, Humphries SE and Henney AM: Progression of coronary atherosclerosis is associated with a common genetic variant of the human stromelysin- 1 promoter which results in reduced gene expression. J Biol Chem 271: 13055-13060, 1996.

24. Thompson MW, Mcinnes RR and Willard HF: Genetics in Medicine. 5th edition. Thompson \& Thompson, Philadelphia, p500, 1991.

25. Zhu C, Odeberg J, Hamsten A and Eriksson P: Allele-specific MMP-3 transcription under in vivo conditions. Biochem Biophys Res Commun 348: 1150-1156, 2006.

26. Deguara J, Burnand KG, Berg J, et al: An increased frequency of the $5 \mathrm{~A}$ allele in the promoter region of the MMP3 gene is associated with abdominal aortic aneurysms. Hum Mol Genet 16: 3002-3007, 2007

27. Mauviel A: Cytokine regulation of metalloproteinase gene expression. J Cell Biochem 53: 288-295, 1993.

28. Millward-Sadler SJ, Wright MO, Davies LW, Nuki G and Salter DM: Mechanotransduction via integrins and interleukin-4 results in altered aggrecan and matrix metalloproteinase 3 gene expression in normal, but not osteoarthritic, human articular chondrocytes. Arthritis Rheum 43: 2091-2099, 2000.

29. Borghaei RC, Rawlings PL Jr, Javadi $M$ and Woloshin J: NF-kappaB binds to a polymorphic repressor element in the MMP-3 promoter. Biochem Biophys Res Commun 316: 182-188, 2004

30. Cesari M, Penninx BW, Newman AB, et al: Inflammatory markers and onset of cardiovascular events: results from the Health ABC study. Circulation 108: 2317-2322, 2003.

31. Burger-Kentischer A, Goebel H, Seiler R, et al: Expression of macrophage migration inhibitory factor in different stages of human atherosclerosis. Circulation 105: 1561-1566, 2002.

32. Humphries SE, Luong LA, Talmud PJ, et al: The 5A/6A polymorphism in the promoter of the stromelysin-1 (MMP-3) gene predicts progression of angiographically determined coronary artery disease in men in the LOCAT Gemfibrozil Study. Atherosclerosis 139: 49-56, 1998.

33. Hirashiki A, Yamada Y, Murase Y, et al: Association of gene polymorphisms with coronary artery disease in low- or high-risk subjects defined by conventional risk factors. J Am Coll Cardiol 42: $1429-1437,2003$

34. Lamblin N, Bauters C, Hermant X, Lablanche JM, Helbecque N and Amouyel P: Polymorphisms in the promoter regions of MMP-2, MMP-3, MMP-9 and MMP-12 genes as determinants of aneurysmal coronary artery disease. J Am Coll Cardiol 40 43-48, 2002

35. Terashima M, Akita H, Kanazawa K, et al: Stromelysin promoter $5 \mathrm{~A} / 6 \mathrm{~A}$ polymorphism is associated with acute myocardial infarction. Circulation 99: 2717-2719, 1999.

36. Yoon S, Tromp G, Vongpunsawad S, Ronkainen A, Juvonen T and Kuivaniemi H: Genetic analysis of MMP3, MMP9, and PAI-1 in Finnish patients with abdominal aortic or intracranial aneurysms. Biochem Biophys Res Commun 265: 563-568, 1999.
37. Flex A, Gaetani E, Angelini F, et al: Pro-inflammatory genetic profiles in subjects with peripheral arterial occlusive disease and critical limb ischemia. J Intern Med 262: 124-130, 2007.

38. Ghilardi G, Biondi MA, DeMonti M, Turri O, Guagnellini E and Scorza R: Matrix metalloproteinase-1 and matrix metalloproteinase-3 gene promoter polymorphisms are associated with carotid artery stenosis. Stroke 33: 2408-2412, 2002.

39. Humphries SE, Martin S, Cooper J and Miller G: Interaction between smoking and the stromelysin-1 (MMP3) gene 5A/6A promoter polymorphism and risk of coronary heart disease in healthy men. Ann Hum Genet 66: 343-352, 2002.

40. White AJ, Duffy SJ, Walton AS, et al: Matrix metalloproteinase-3 and coronary remodelling: implications for unstable coronary disease. Cardiovasc Res 75: 813-820, 2007.

41. Beyzade S, Zhang S, Wong YK, Day IN, Eriksson P and Ye S: Influences of matrix metalloproteinase-3 gene variation on extent of coronary atherosclerosis and risk of myocardial infarction. J Am Coll Cardiol 41: 2130-2137, 2003.

42. Schwarz A, Haberbosch W, Tillmanns H and Gardemann A: The stromelysin-1 $5 \mathrm{~A} / 6 \mathrm{~A}$ promoter polymorphism is a disease marker for the extent of coronary heart disease. Dis Markers 18: $121-128,2002$.

43. Silence J, Collen D and Lijnen HR: Reduced atherosclerotic plaque but enhanced aneurysm formation in mice with inactivation of the tissue inhibitor of metalloproteinase-1 (TIMP-1) gene. Circ Res 90: 897-903, 2002.

44. Dollery CM, McEwan JR and Henney AM: Matrix metalloproteinases and cardiovascular disease. Circ Res 77: 863-878, 1995.

45. Henney AM, Wakeley PR, Davies MJ, et al: Localization of stromelysin gene expression in atherosclerotic plaques by in situ hybridization. Proc Natl Acad Sci USA 88: 8154-8158, 1991.

46. Loftus IM, Naylor AR, Goodall S, Crowther M, Jones L, Bell PR and Thompson MM: Increased matrix metalloproteinase-9 activity in unstable carotid plaques: a potential role in acute plaque disruption. Stroke 31: 40-47, 2000 .

47. Medley TL, Kingwell BA, Gatzka CD, Pillay P and Cole TJ: Matrix metalloproteinase-3 genotype contributes to age-related aortic stiffening through modulation of gene and protein expression. Circ Res 92: 1254-1261, 2003.

48. Boutouyrie P, Tropeano AI, Asmar R, et al: Aortic stiffness is an independent predictor of primary coronary events in hypertensive patients: a longitudinal study. Hypertension 39: 10-15, 2002.

49. Kingwell BA, Waddell TK, Medley TL, Cameron JD and Dart AM: Large artery stiffness predicts ischemic threshold in patients with coronary artery disease. J Am Coll Cardiol 40: 773-779, 2002

50. Park J, Shin KS and Kim YW: Polymorphism of matrix metalloproteinase-3 promoter gene as a risk factor for coronary artery lesions in Kawasaki disease. J Korean Med Sci 20: 607-611, 2005.

51. Marfella R, D'Amico M, Esposito K, et al: The ubiquitin-proteasome system and inflammatory activity in diabetic atherosclerotic plaques: effects of rosiglitazone treatment. Diabetes 55: 622-632, 2006.

52. Chen QJ, Lu L, Peng WH, et al: Polymorphisms of MMP-3 and TIMP-4 genes affect angiographic coronary plaque progression in non-diabetic and type 2 diabetic patients. Clin Chim Acta 405: 97-103, 2009.

53. Takahashi M, Haro H, Wakabayashi Y, Kawa-uchi T, Komori H and Shinomiya K: The association of degeneration of the intervertebral disc with $5 \mathrm{a} / 6 \mathrm{a}$ polymorphism in the promoter of the human matrix metalloproteinase-3 gene. J Bone Joint Surg 83B: 491-495, 2001

54. Kauppila LI: Can low-back pain be due to lumbar-artery disease? Lancet 346: 888-889, 1995.

55. Hirata H, Okayama N, Naito K, et al: Association of a haplotype of matrix metalloproteinase (MMP)-1 and MMP-3 polymorphisms with renal cell carcinoma. Carcinogenesis 25: 2379-2384, 2004.

56. Biondi ML, Turri O, Leviti S, et al: MMP-1 and MMP-3 polymorphisms in promoter regions and cancer. Clin Chem 46: 2023-2024, 2000

57. Lei H, Zaloudik J and Vorechovsky I: Lack of association of the 1171 (5A) allele of the MMP3 promoter with breast cancer. Clin Chem 48: 798-799, 2002

58. Krippl P, Langsenlehner U, Renner W, et al: The 5A/6A polymorphism of the matrix metalloproteinase 3 gene promoter and breast cancer. Clin Cancer Res 10: 3518-3520, 2004. 
59. Holliday DL, Hughes S, Shaw JA, Walker RA and Jones JL: Intrinsic genetic characteristics determine tumor-modifying capacity of fibroblasts: matrix metalloproteinase-3 5A/5A genotype enhances breast cancer cell invasion. Breast Cancer Res 9: 67, 2007.

60. Vairaktaris E, Yapijakis C, Vasiliou S, et al: Association of -1171 promoter polymorphism of matrix metalloproteinase-3 with increased risk for oral cancer. Anticancer Res 27: 4095-4100, 2007.

61. Okamoto K, Mandai M, Mimura K, Murawaki Y and Yuasa I: The association of MMP-1, -3 and -9 genotypes with the prognosis of $\mathrm{HCV}$-related hepatocellular carcinoma patients. Res Commun Mol Pathol Pharmacol 117-118: 77-89, 2005.

62. Beeghly-Fadiel A, Xiang YB, Deming SL, et al: No association between matrix metalloproteinase (MMP)-1, MMP-3, and MMP-7 SNPs and endometrial cancer risk. Cancer Epidemiol Biomarkers Prev 18: 1925-1928, 2009.

63. Lu Z, Cao Y, Wang Y, et al: Polymorphisms in the matrix metalloproteinase-1, 3, and 9 promoters and susceptibility to adult astrocytoma in northern China. Neurooncol 85: 65-73, 2007.

64. Zinzindohoué F, Lecomte T, Ferraz JM, et al: Prognostic significance of MMP-1 and MMP-3 functional promoter polymorphisms in colorectal cancer. Clin Cancer Res 11: 594-599, 2005 .

65. Szyllo K, Smolarz B, Romanowicz-Makowska H, Niewiadomski M, Kozlowska E and Kulig A: The promoter polymorphism of the matrix metalloproteinase 3 (MMP-3) gene in women with ovarian cancer. J Exp Clin Cancer Res 21: 357-361, 2002

66. Kader AK, Shao L, Dinney CP, et al: Matrix metalloproteinase polymorphisms and bladder cancer risk. Cancer Res 66 11644-11648, 2008.

67. Terry CF, Loukaci V and Green FR: Cooperative influence of genetic polymorphisms on interleukin 6 transcriptional regulation. J Biol Chem 275: 18138-18144, 2000.

68. Garner $\mathrm{C}$ and Slatkin M: On selecting markers for association studies: patterns of linkage disequilibrium between two and three diallelic loci. Genet Epidemiol 24: 57-67, 2003.

69. Fang S, Jin X, Wang R, et al: Polymorphisms in the MMP1 and MMP3 promoter and non-small cell lung carcinoma in North China. Carcinogenesis 26: 481-486, 2005.

70. Greendale GA, Chu J, Ferrell R, Randolph JF Jr, Johnston JM and Sowers MR: The association of bone mineral density with estrogen receptor gene polymorphisms. Am J Med 119: S79-S86, 2006 .

71. Ju W, Kim JW, Park NH, Song YS, Kim SC, Kang SB and Lee HP: Matrix metalloproteinase-1 promoter polymorphism and epithelial ovarian cancer: does ethnicity matter? J Obstet Gynaecol 33: 155-160, 2007.

72. Braunwald E: Unstable angina: a classification. Circulation 80 : 410-414, 1989.
73. Samnegård A, Silveira A, Lundman $\mathrm{P}$, et al: Serum matrix metalloproteinase-3 concentration is influenced by MMP-3$16125 \mathrm{~A} / 6 \mathrm{~A}$ promoter genotype and associated with myocardial infarction. J Intern Med 258: 411-419, 2005.

74. Lanfear DE, Marsh S, Cresci S, Shannon WD, Spertus JA and McLeod HL: Genotypes associated with myocardial infarction risk are more common in African Americans than in European Americans. J Am Coll Cardiol 44: 165-167, 2004.

75. Scherer S, de Souza TB, de Paoli J, et al: Matrix metalloproteinase gene polymorphisms in patients with rheumatoid arthritis. Rheumatol Int 30: 369-373, 2010.

76. Hall NF, Gale CR, Ye S and Martyn CN: Myopia and polymorphisms in genes for matrix metalloproteinases. Invest Ophthalmol Vis Sci 50: 2632-2636, 2009.

77. Wei JC, Lee HS, Chen WC, Shiu LJ, Yang SF and Wong RH Genetic polymorphisms of the matrix metalloproteinase-3 (MMP-3) and tissue inhibitors of matrix metalloproteinases-1 (TIMP-1) modulate the development of ankylosing spondylitis Ann Rheum Dis 68: 1781-1786, 2009.

78. Ozkök E, Aydin M, Babalik E, Ozbek Z, Ince N and Kara I Combined impact of matrix metalloproteinase-3 and paraoxonase $155 / 192$ gene variants on coronary artery disease in Turkish patients. Med Sci Monit 14: 536-542, 2008.

79. Djurić T, Zivković M, Radak D, et al: Association of MMP-3 $5 \mathrm{~A} / 6 \mathrm{~A}$ gene polymorphism with susceptibility to carotid atherosclerosis. Clin Biochem 41: 1326-1329, 2008.

80. Kara I, Ozkok E, Aydin M, et al: Combined effects of ACE and MMP-3 polymorphisms on migraine development. Cephalalgia 27: 235-243, 2007.

81. Liu PY, Li YH, Chan SH, Lin LJ, Wu HL, Shi GY and Chen JH: Genotype-phenotype association of matrix metalloproteinase-3 polymorphism and its synergistic effect with smoking on the occurrence of acute coronary syndrome. Am J Cardiol 98: 1012-1017, 2006

82. Liu PY, Chen JH, Li YH, Wu HL and Shi GY: Synergistic effect of stromelysin-1 (matrix metalloproteinase-3) promoter $5 \mathrm{~A} / 6 \mathrm{~A}$ polymorphism with smoking on the onset of young acute myocardial infarction. Thromb Haemost 90: 132-139, 2003.

83. Ghilardi G, Biondi ML, Caputo M, et al: A single nucleotide in the matrix metalloproteinase 3 promoter enhances breast cancer susceptibility. Clin Cancer Res 8: 3820-3823, 2002.

84. Hinoda Y, Okayama N, Takano N, et al: Association of functional polymorphisms of matrix metalloproteinase (MMP)-1 and MMP-3 genes with colorectal cancer. Int J Cancer 102: 526-529, 2002.

85. Flex A, Gaetani E, Proia AS, et al: Analysis of functional polymorphisms of metalloproteinase genes in persons with vascular dementia and Alzheimer's disease. J Gerontol A Biol Sci Med Sci 61: 1065-1069, 2006. 